\title{
WAVE GROWTH UNDER VARIABLE WIND CONDITIONS
}

\author{
Marta Alomar ${ }^{1}$, Rodolfo Bolaños- Sánchez ${ }^{2}$, Agustín Sanchez-Arcilla ${ }^{1}$ and Abdel Sairouni ${ }^{3}$ \\ ${ }^{1}$ Technical University of Catalonia, marta.alomar@upc.edu, agustin.arcilla@upc.edu \\ ${ }^{2}$ National Oceanography Center (NOC), rbol@pol.ac.uk \\ ${ }^{3}$ Meteorological Service of Catalonia (SMC), asairouni@meteocat.cat
}

Parametric wave growth curves are commonly used to empirically calculate wave height under fetch limited conditions and to tune the source functions of spectral wave models. There is not a unique wave growth function and many deviations from the first similarity laws have been reported. The applicability of the commonly used functions in variable wind conditions is expected to be limited. In this study we calculated wave growth curves with data from an instrumental set-up in the north-western Mediterranean. This region is characterized by non-homogeneous wind conditions (both in time and space). The first growth functions we calculated from the observations suggested higher wave growth rates than previously described by other authors. A close look to the sources of discrepancy in the calculations under such wind conditions revealed the importance to accurately separate sea from swell and to use only locally generated sea. The source of the wind data used for the scaling law is thought to be responsible for the remaining discrepancies from the commonly used growth functions. Wind and wave data from a high resolution simulation were used to calculate the growth functions from a spectral wave model, and to explore the importance of using in-situ wind measures to scale the variables. Simulated wave growth rates are lower than observed and lower than previously reported by other authors. Wind measurements from the most offshore buoy seem to be representative enough of the winds over the entire area. The results support the applicability of the well-known functions in the region of interest when certain conditions are met; i.e. pure wind sea conditions, and choosing a representative wind speed to scale the variables.

Keywords: variable winds; wave growth; fetch-limited; wave model; SWAN

\section{INTRODUCTION}

Wave growth can be described as the non-dimensional evolution of wave parameters along the fetch. The first similarity law was suggested by Kitaigorodskii (1962) (see, e.g. Kahma and Calkoen 1992; herefater KC92); it described the growth of wave energy (and peak frequency shift) along the fetch.

Parametric wave growth curves are since then commonly used to empirically calculate wave height under fetch limited conditions (e.g. inner basins, lakes). The experimentally measured wave growth functions are also used to tune the source functions of spectral wave models (Bottema and van Vledder 2009) and to validate its wind wave generation processes. However, there is not a unique wave growth function and many deviations from the first similarity law for growing seas have been reported (KC92). The first functions were calculated during uniform and steady wind blowing perpendicular offshore (fetch-limited conditions).

Non-dimensional wave energy $\left(\bar{E}=g^{2} \times E / U^{4}\right)$, peak frequency $(\bar{\omega}=\mathrm{U} \times \omega / \mathrm{g})$, and fetch $\left(\bar{X}=\mathrm{g} \times \mathrm{X} / \mathrm{U}^{2}\right)$ are calculated as decribed by Kitaigorodskii (1962) (in KC92), where $g$ is the gravity and $U$ the wind speed. In the literature, wave growth functions have also been derived under physical conditions that deviate from the ideal conditions such as the stability of the atmosphere (KC92), the morphology of the fetch (Pettersson 2004), and strongly varying wind conditions in time (Donelan et al. 1985). In Donelan et al. (1985) both wind speed and wind direction were varying in time. They considered more valuable to describe the parameters of the waves in terms of local conditions and used on the $\mathrm{x}$-axis the inverse wave age $\mathrm{U}_{\mathrm{c}} / \mathrm{c}_{\mathrm{p}}$, which is the relation of the wind speed and the celerity of the waves at the spectral peak in the wind direction. In KC92 they adjusted Donelan et al. (1985)'s curves to the commonly used curves $\left(\overline{\mathrm{E}}_{\mathrm{vs}} \overline{\mathrm{X}}\right)$ to compare both set of functions in the same terms. The resulting functions had similar development rates (see Table 1). In this work, we focused on the most commonly used functions reviewed in KC92 to study their applicability during variable wind conditions. 


\begin{tabular}{|l|c|c|l|}
\hline \multicolumn{3}{|l|}{ Table 1. Wave growth functions described by previous authors (as reviewed in KC92). } \\
\hline Authors & $\begin{array}{c}\text { Development rate } \\
(\mathrm{b})\end{array}$ & $\begin{array}{c}\text { Origin } \\
(\mathrm{a})\end{array}$ & Characteristics \\
\hline Hasselmann et al. (1973) & 1 & $1.6^{*} 10^{-1}$ & \\
Kahma (1981) & 1 & $3.5^{\star} 10^{-7}$ & \\
Kahma and Calkoen (1992) & 0.77 & $9.3^{*} 10^{-1}$ & Stable \\
Donelan et al. (1985) & 0.94 & $5.4^{*} 10^{-7}$ & Unstable \\
& 1 & $2.8^{*} 10^{-7}$ & Stable \\
Hwang and Wang (2004) & 1 & $3.8^{*} 10^{-/}$ & Unstable \\
& 0.81 & $6.2^{*} 10^{-7}$ & $1^{\text {st }}$ order \\
& $1.8-2 \cdot 0.06 \cdot \ln \bar{X}$ & $e^{-17.6} \cdot \bar{X}^{0.06 \cdot \ln \bar{X}}$ & $2^{\text {nd } \text { order }}$ \\
\hline
\end{tabular}

Wave growth under spatially varying wind conditions has received comparatively limited research attention. There is a limitation in knowledge that has direct implications for coastal predictions. For this reason, in this work we study the wave growth curves in a region with high spatial variability in the wind fields: the NW Mediterranean Sea. We used data from three buoys along the main offshore wind direction. Data were collected during two months and they were used to estimate the non-dimensional wind wave growth functions in the area, where no previous functions have been ever derived. The first analysis showed an apparent enhanced growth when compared with previously reported functions. However, its in-depth study revealed that the discrepancies with the reference functions were reduced under certain conditions. As expected, the closer the ideal conditions were full-filled, the closer the development rates were to those previously reported (see Table 1 and KC92 for a review of previous observations). In our data set the main sources of discrepancy were found to be the accurate separation of the sea/swell systems and the location of the wind speed used to non-dimensionalize the variables.

We investigated the uncertainty associated to adjusting the fetch to the wind direction, but we did not observe important differences in the growth rates. Also, we calculated the wave growth curves from numerically simulated wave data during a specific fetch-limited storm event. The growth rates from the simulations are lower than those from the observations and lower than the functions in KC92, but within their confidence intervals. Wind speed measurements at each buoy (in-situ) are thought to be the best option to non-dimensionalize the variables. According to the simulated data, in this region, wind measurements at the most offshore also seem to be representative of the wind in the area, and the resulting growth rates agree well with those in $\mathrm{KC} 92$.

\section{EXPERIMENTAL DATA}

In this study, experimental data were collected from an array of instruments located in the Southern Catalan coast (NW Mediterranean Sea) (see Figure 1). In this region, and during global north wind conditions, the complexity of the coastal orography induces an off-shore flow following a typical north-west direction. These characteristic land-to-sea winds (Mestral in the local vernacular) present wind jets associated to the channeling effect of the rivers and the breaches in the coastal mountain range; and they generate growing waves along the northwest direction in fetch-limited conditions. In contrast, the spatial distribution of the wind speed and its persistence in time is far from the ideal conditions usually met when calculating fetch-limited wave growth functions. The period of study spans months from November 2007 to January 2008. 


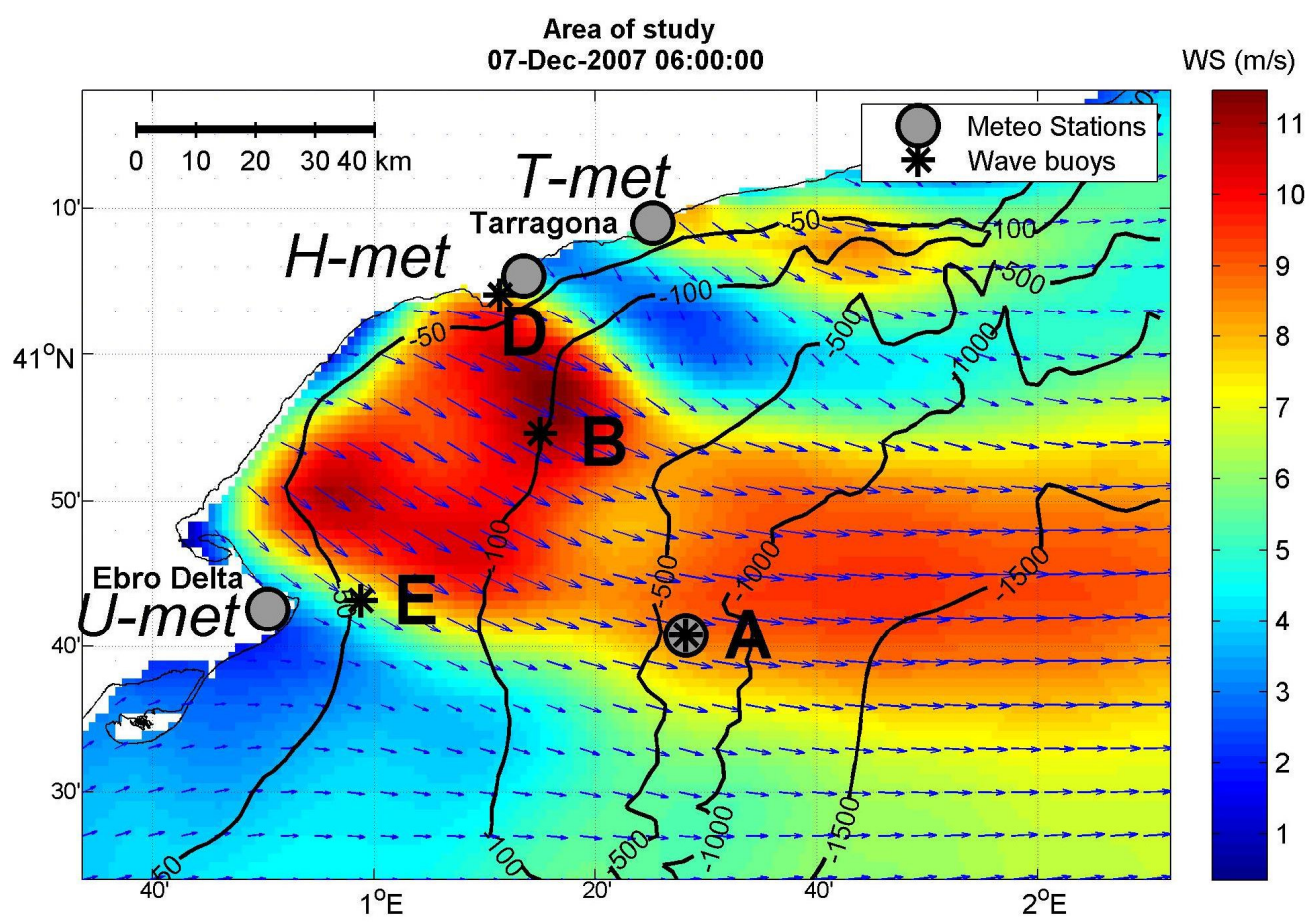

Figure 1. Study area and wave model domain. Wave recording instruments (black stars) and meteorological stations (grey circles) are shown. The color representation shows a simulation of the wind speed during a specific offshore wind event. The arrows indicate the wind direction.

Wind speed, wind direction and air temperature were measured at four different positions: a metoceanographic buoy located 50km offshore (A), and three automatic meteorological stations located on Tarragona harbor's breakwater (H-Met), and 20km northeast (T-Met; Torredembarra) and 60km southwest (U-Met; Illa de Buda) of the harbor. Wind data at buoy A were measured at $3 \mathrm{~m}$ high and then interpolated to $10 \mathrm{~m}$ high assuming a logarithmic wind profile (Charnock's parameter equal to $0.04)$. Measurements at the other instruments are given at $10 \mathrm{~m}$ height.

Wave parameters were recorded at a set of four buoys. The most offshore one is the metoceanographic buoy A. It is a directional pitch-roll buoy (Seawatch) that also measures water temperature at $1 \mathrm{~m}$ depth. Buoy A is part of the government's buoy network (Puertos del Estado) and is located $55 \mathrm{~km}$ offshore at $688 \mathrm{~m}$ depth. Between buoy A and the harbor, approximately along the direction of the characteristic northwest wind, a scalar buoy (B) was deployed in December 2007 until January 2008 within the Spanish project RIMA. Buoy B is a Datawell scalar buoy that was temporally located $20 \mathrm{~km}$ offshore at $93 \mathrm{~m}$ depth. Even closer to the coast there is another scalar waverider buoy from Puertos del Estado: buoy D is located only $1 \mathrm{~km}$ offshore at $22 \mathrm{~m}$ depth. We have also used wave data from another instrument located 50km south from Tarragona harbor: buoy E is a directional pitchroll Waverider buoy located $8 \mathrm{~km}$ offshore (23km along the northwest direction) at $60 \mathrm{~m}$ depth. It is part of the regional network XIOM (Bolaños et al. 2009). Wave data is recorded hourly except at buoy B, where wave data is measured three times per hour. All wind and wave instruments are depicted in Figure 1 .

It must be noted that bimodal sea states are very common in this region (Bolaños et al. 2009). Because we are interested in pure wave growth along the northwest fetch, we separated wave systems using the one dimensional partitioning criteria reviewed in Portilla et al. (2009). Frequency spectra were first smoothed and then partitioned according to Portilla et al. (2009) with two slight modifications. First, we used the peak frequency of each partition (instead of the mean frequency) as a criterion to combine partitions. Second, we combined partitions which peak frequency was closer than $0.015 \mathrm{~Hz}$ to the separation frequency (lowest frequency between two energy partitions) and/or which energy was lower than $8 \%$ the total energy of the spectrum. To identify sea from swell there exist several different methods (some of which are reviewed in Portilla et al. 2009). A common method in regions where sea and swell are very different in the frequency space consists in setting a constant splitting frequency. This method is suitable because it does not use any wind information and avoids choosing one meteorological station over another in variable regions like ours. For this reason, sea and 
swell were first split apart using a fixed frequency of $0.13 \mathrm{~Hz}$ based on visual observations: during a specific fetch-limited storm event, the peak frequency of the generated waves at the different buoys was rarely lower than $0.13 \mathrm{~Hz}$. Later on, we used the growth curves derived by KC92 to find the expected peak frequency for the measured wind speed and added a 30\% margin of error to set a separation frequency $\left(f_{s}\right)$ between locally generated sea and swell. If the peak frequency was larger than $\mathrm{f}_{\mathrm{s}}$ the system was identified as locally generated sea. Wind data was taken from the offshore buoy A, which we suspected to be the most representative station of wind data along the fetch. We also used wind data from the other meteorological stations to assess its influence on the calculated curves.

Because up to date there is no consensus on the influence of swell on growing seas (Ardhuin et al. 2007, Hwang 2008), in the non-dimensional analysis we have only used pure unimodal wind sea spectra; i.e. only one energy peak was identified in the frequency domain.

\section{WAVE GROWTH IN VARIABLE WIND CONDITIONS}

To describe wave growth according to the functions in KC92 it is common to use the development rate (b), which describes the rate of growth of the waves along the fetch $\left(\bar{E}=a \cdot \bar{X}^{b}\right)$. In a $\log -\log$ representation of the dimensionless variables the slope of the regression line corresponds to the development rate (b) of the energy (or the frequency) along the fetch (see also the Appendix). In the plot (e.g. Figure 2), on the lower-left corner of the figure we expect to encounter short fetch, low energy and/or high wind speed data. On the upper-right corner we expect to find long fetch, high energy, and/or low wind speed data. Previous observations are summarized in KC92; they all report development rates smaller or equal to $1(b \leq 1)$ (see Table 1$)$.

The energy wave growth curves have been calculated using the measurements described in previous section and are shown in Figure 2 (upper plot). We selected one-peaked sea states and winds blowing offshore $\left(315^{\circ} \pm 30^{\circ}\right)$. The scaling wind speed was taken from measurements at the most offshore buoy A. We observe that growth rates (slope of the regression line) at all buoys are greater than 1, the maximum value reported by previous authors. The highest growth rates are observed at the buoys with shorter fetch (B and E) where no in-situ wind information was available. In Table 2, the different settings and data used to calculate the growth functions are described. The development rates obtained for each different setting is given in Table 3. The development rates from data at individual buoys are given together with the rates calculated using data from all buoys because no in-situ wind speed is measured at buoys B and E. For this reason the calculations at these locations have a larger degree of uncertainty that is important to consider. We will see that although discrepancies at these two buoys are usually larger than at A, the closer we get to the ideal conditions, the less important they become.

\begin{tabular}{|c|c|c|c|c|c|}
\hline No & $\begin{array}{l}\text { Period } \\
\text { of } \\
\text { time }\end{array}$ & $\begin{array}{l}\text { Sea/swell } \\
\text { separation } \\
\text { method }\end{array}$ & $\begin{array}{l}\text { (Fetch along) } \\
\text { Direction } \theta\end{array}$ & $\begin{array}{l}\text { Min. } \\
U_{10} \\
\left(\mathrm{~ms}^{-1}\right)\end{array}$ & $\begin{array}{l}\text { Scaling } \\
\text { wind } \\
\text { location }\end{array}$ \\
\hline 1 & All & $\mathrm{f}_{\mathrm{s}}=0.13 \mathrm{~Hz}$ & $315^{\circ}$ & 0 & Buoy A \\
\hline 2 & All & $\mathrm{f}_{\mathrm{s}}=0.13 \mathrm{~Hz}$ & $315^{0}$ & 5 & Buoy A \\
\hline 3 & All & KC92 & $315^{\circ}$ & 0 & Buoy A \\
\hline 4 & Subset & $\mathrm{f}_{\mathrm{s}}=0.13 \mathrm{~Hz}$ & $315^{\circ}$ & 0 & Buoy A \\
\hline 5 & Subset & KC92 & $315 \pm 30^{\circ}$ & 0 & Buoy A \\
\hline 6 & Subset & KC92 & $315 \pm 30^{\circ}$ & 0 & H-met \\
\hline
\end{tabular}

\begin{tabular}{|c|c|c|c|c|c|c|c|c|}
\hline \multirow[t]{2}{*}{$\mathrm{N}^{0}$} & \multicolumn{2}{|c|}{$A$} & \multicolumn{2}{|c|}{$B$} & \multicolumn{2}{|c|}{$E$} & \multicolumn{2}{|c|}{ All buoys } \\
\hline & $b$ & $S I$ & $b$ & SI & B & $S I$ & $b$ & SI \\
\hline 1 & 1.33 & 0.52 & 1.59 & 0.55 & 1.65 & 0.55 & 1.49 & 0.69 \\
\hline 2 & 0.8 & 0.39 & 1.12 & 0.45 & 1.3 & 0.47 & 0.95 & 0.47 \\
\hline 3 & 0.85 & 0.36 & 1.07 & 0.39 & 1.18 & 0.42 & 0.91 & 0.41 \\
\hline 4 & 1.03 & 0.31 & 1.18 & 0.37 & 1.13 & 0.45 & 1 & 0.38 \\
\hline 5 & 0.98 & 0.31 & 1.02 & 0.36 & 0.86 & 0.39 & 0.91 & 0.36 \\
\hline 6 & 1.69 & 0.49 & 1.62 & 0.41 & 1.71 & 0.39 & 1.49 & 0.54 \\
\hline
\end{tabular}



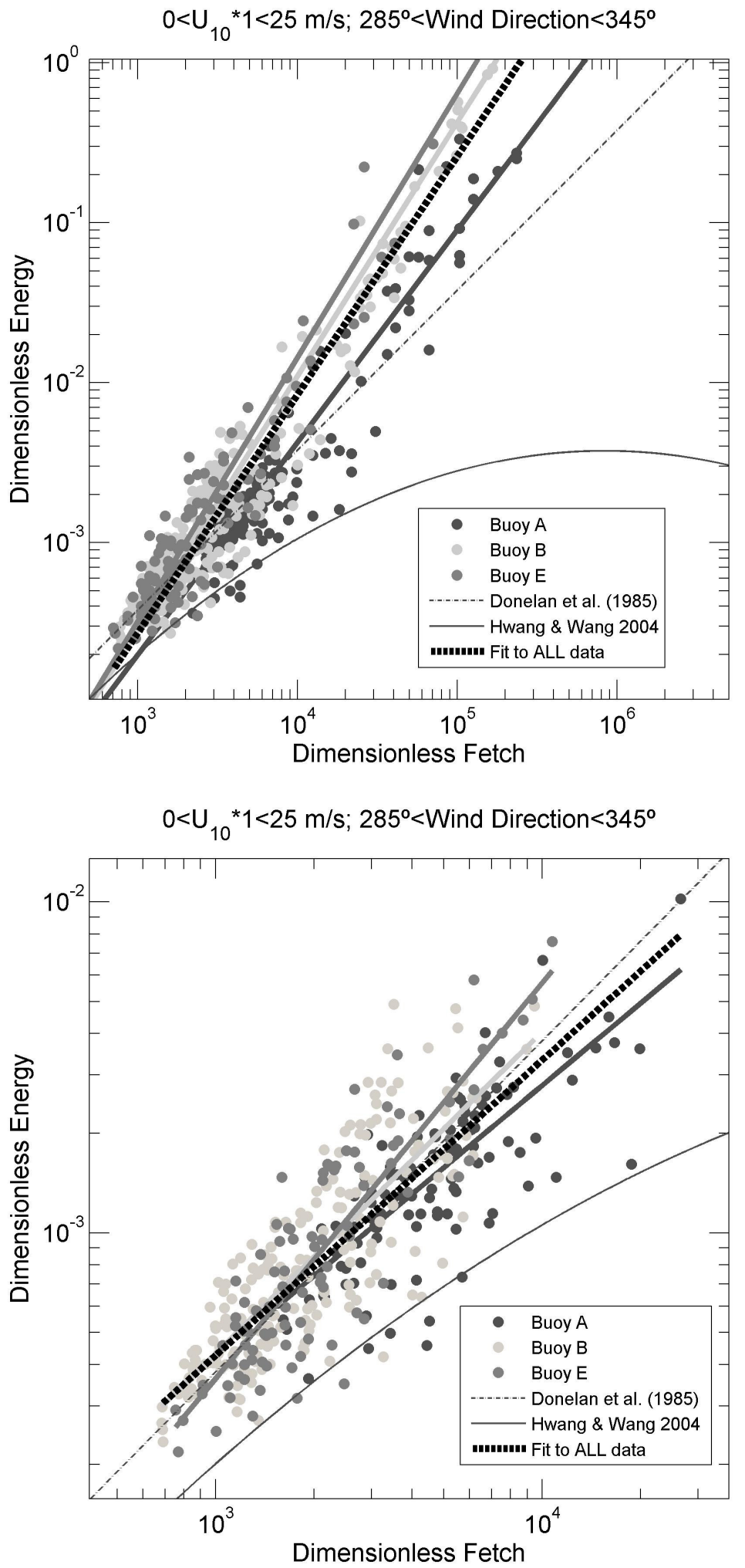

Figure 2. Non-dimensional curves at buoys A, B and E. Sea and swell were separated using a fixed frequency $(0.13 \mathrm{~Hz})$ (upper figure), and KC92 curves (lower figure). The wind speeds to scale the variables have been taken from buoy A. Solid lines indicate the fit to the data points (same color code). The functions reported in Donelan et al. (1985) and Hwang and Wang (2004) are also plotted. 
The reason of the larger growth rates can be searched for in the scaling law used, which was derived to be used in homogenous and constant wind conditions only. In this scaling law (as in KC92) the wind speed scales the variables in the X-axis (fetch) and in the Y-axis (energy or peak frequency); thus the importance of accurately selecting the wind speed used.

On one side, many discrepancies are related to the choice of the best wind speed that describes the turbulent boundary layer (Komen et al. 1994): the wind speed at $10 \mathrm{~m}$ height $\left(\mathrm{U}_{10}\right)$ or the friction velocity $\left(\mathrm{u}_{*}\right)$, which is a velocity scale related to wind stress. In Komen et al. (1994) they report a better agreement between observed growth rates when using $u_{*}$. Young and Verhagen (1996) compared both parameters and concluded that less uncertainty was introduced when using $U_{10}$. In this study, because we do not have measurements of $u_{*}$, we computed $u_{*}$ using the Drennan et al. (2003)'s relationship for pure wind sea conditions. The growth rates we observe using $\mathrm{u}_{*}$ are slightly higher than using $\mathrm{U}_{10}$ and higher than the values reported in KC92. The reason probably is the calculation of $\mathrm{u}_{*}$, which depends on $\mathrm{U}_{10}$ and the celerity of the peak: variables that change both in time and space. Because of the higher degree of uncertainty introduced when using $\mathrm{u}_{*}$ (Young and Verhagen 1996) we decided to use $U_{10}$ rather than $\mathrm{u}_{*}$ in further calculations.

On the other side, the discrepancies between the observed rates and the reference functions could be due to the location-of-measure of the wind speed used in the scaling law (i.e. the meteorological station where the data was measured at). Dobson et al. (1989) investigated the suitability of using fetchaveraged winds, instead of in-situ measurements, but assumed that wind speed increase from the coast and offshore. Although they considered that fetch averaged winds are the most appropriate scaling variable because they represent a time and space history of the wave field, they acknowledged that choosing the best winds is still an open question. In the region of study we declined to use averaged winds because an increasing wind speed profile from the coast towards offshore could not be assumed. In the simulated wind fields shown in Figure 1 we observe for example that the highest wind speeds along the fetch of buoy A, are not at the buoy itself (the most offshore position) but at about 20km from the coast. This problem was previously pointed out in Alomar et al. (2009). The role of varying winds along the fetch is especially important when scaling wave growth parameters in highly variable wind conditions. Because wind measurements are usually not available everywhere along the fetch (in this case there are four meteorological stations), we need to investigate the effect of the scaling wind speed source in determining wave growth curves when no other data is available; and choose the most representative wind source along the fetch. We suspect that one of the reasons of the higher rates observed at buoys B and E is the lack of in-situ wind speeds (at each buoy's position) to nondimensionalize the variables. To check the role of the different wind stations on the calculated growth rates we have computed the curves again using data from the four different meteorological stations in the scaling law. We observe that growth rates increase (and move away from the reference rates) as the meteorological station is farther apart from the wave measurements (we expect it to be less representative of the wind field). But the differences are not very important and do not seem to explain the discrepancies observed.

Another possible reason that we analyzed to explain the observed discrepancies in the growth rates is the value of the fetch. Because the generating wind is also changing in direction (and might not be constant from the coast and offshore) it is very difficult to select an exact value of fetch (distance along which the wind is blowing). To assess the influence of fetch on the obtained growth rates we have adjusted the fetch as the distance from the buoy to the coast on the wind direction $(\theta)$. Although the fetch can change as much as $13 \mathrm{~km}$ (at buoy A; see Table 4 num.5). The so-calculated growth rates decrease slightly but not enough to explain the large deviations from the previously-reported values.

\begin{tabular}{|c|c|c|c|c|}
\hline \multirow[t]{2}{*}{ Buoy } & \multicolumn{3}{|c|}{$\begin{array}{c}X \\
\text { Distance to the coast along } \theta\end{array}$} & \multirow{2}{*}{$\begin{array}{c}\bar{X} \\
\text { for } \theta=315^{\circ} \text { and } U_{10}=10 \mathrm{~ms}^{-1}\end{array}$} \\
\hline & $285^{\circ}$ & $315^{\circ}$ & $345^{\circ}$ & \\
\hline A & 64 & 56 & 51 & $5.5^{\star} 10^{3}$ \\
\hline B & 30 & 24 & 20 & $2.4^{*} 10^{3}$ \\
\hline D & 0.9 & 1 & 1.7 & $0.1^{*} 10^{3}$ \\
\hline $\mathrm{E}$ & 15 & 22 & 28 & $2.2^{*} 10^{3}$ \\
\hline
\end{tabular}

The uncertainties related to the applicability of the scaling law in variable wind conditions were not causing the large discrepancies first observed. A closer look to the data points itself shows that the points that significantly increase the slope of the wave growth functions are the high non-dimensional energy and fetch ones (upper-right corner of Figure 2 (upper plot)). Note that because we only have 
three different buoys (and three different physical fetch values) the range of non-dimensional fetch is given by the different wind speeds recorded (see Table 4 for an example of non-dimensional fetch at each buoy and fixed wind speed). Wave data recorded during low wind speed periods are displayed on the figure's right hand side. According to the growth functions in KC92, at short fetch (or low wind speed) the energy levels should be accordingly low. But this does not seem to be the case: during low wind speeds it looks like the energy is much higher than expected from the reference curves. If we do not take into account low wind speed condition $\left(\mathrm{U}_{10}<5 \mathrm{~ms}^{-1}\right)$ the growth rates decrease; and the discrepancies with the previously-reported rates also decrease. In Ardhuin et al. (2007) and Young and Verhagen (1996), for example, low wind speeds were not included in the calculations. During low wind speed conditions (calm periods), winds are generally turning and the existing wave energy is probably 'old sea'. We use the term 'old sea' to refer to wave systems from the same direction than the existing wind regime but that were not generated by it; i.e. waves generated by previous wind conditions (either in time or space). We do not use the term swell because we are not sure to what extent these 'old sea' systems are still growing or not. What is clear is that when old sea/swell is included in the calculations of the wave growth functions, the development rate increases and departs from the reference functions.

The sea/swell identification method using a fixed frequency was chosen to reduce the uncertainty associated to the variability of the wind field; i.e. the representativity of the measurements at a single meteorological station. But because of the presence of old sea systems, in next section we have calculated again the growth functions using the curves of KC92 to separate sea from old sea/swell (see Figure 2 (lower plot)). This method is expected to filter out low wind conditions and old sea data. The growth rate discrepancies can also be reduced when the period of time selected is reduced to pure fetch-limited storm conditions; a subset of data that fulfills these conditions is from the 7 Dec. $5 \mathrm{~h}$ to the 8 Dec. $15 \mathrm{~h}$ and from the 9 Dec. $20 \mathrm{~h}$ to the $11 \mathrm{Dec}$. $13 \mathrm{~h}$. This period of time was selected because no opposing sea/swell was observed, no calm periods were included, and winds were blowing offshore.

No data from the most coastal buoy $\mathrm{D}$ has been plotted because the observed rate is very close to the so-called spurious correlation. A spurious correlation may develop because the common parameter $\mathrm{g} / \mathrm{U}^{2}$ is used to non-dimensionalize the variables on both axis (energy and fetch) (for more details refer to the Appendix, KC92 and Young and Verhagen (1996)). Because the spurious correlation is inherent to the scaling law used, whenever it felt within the $95 \%$ confidence intervals of the observed correlation, both correlations (real, if any, and spurious) could not be told apart. This is the case of all growth functions derived with data from buoy $\mathrm{D}$. The spurious correlation resulting from the dimensional energy and fetch is quadratic $(b=2)$. Buoy $D$ is located very close to the coast in a partially sheltered bay, at the entrance of the harbor. On one side, we expect fetch-limited data to be often contaminated with other swell coming from other directions. Also, we suspect that the buoy might not be able to measure high frequency waves generated in fetchs shorter than $1 \mathrm{~km}$. The expected peak frequency (according to KC92) is too close to the instrument's frequency resolution to rely on the data. When using the separating method based in KC92 curves no data was identified as sea at buoy D.

Note that during the period of study the stability of the atmosphere was generally unstable; i.e. the water was warmer than the air. According to KC92, in these conditions, growth rates are expected to be higher than in stable conditions, but always lower than 1. In this study we could not compare wave growth during stable conditions because almost no data was available.

\section{UNCERTAINTIES IN WAVE GROWTH IN VARIABLE WIND CONDITIONS}

Wave growth curves were recalculated using a sea-swell identification criterion based in KC92 curves, instead of using a fixed frequency. We used the composite data set of KC92, which contains both stable and unstable conditions, with a $30 \%$ uncertainty margin which allows for sea systems with a 30\% lower peak frequency than the value predicted by KC92 curves. The recalculated energy growth rates are much closer to the values reported by previous authors (see Fig. 2 and Table 3 num.4). On one side it can be due to the restriction intrinsic to the sea-swell identification method used, which only selects data along KC92 curves and introduces a certain bias forcing our data to adjust to their curves. We expect that the $30 \%$ error margin greatly reduces the bias imposed to the peak frequency (which might not affect the energy of the growing waves). On the other side, this partitioning method restricts low wind data and simultaneous low peak frequency wave systems; it indirectly takes out low wind speeds from the wave data. Indeed, there is now no important difference between the curves that use the whole wind speed range or those using wind speeds above $5 \mathrm{~ms}^{-1}$ only. Growth rates obtained using the more accurate sea swell partitioning are not very sensitive to adjusting the fetch to the wind direction. In both cases either the mean growth rate, or the possible rates within the $95 \%$ confidence interval fall within the values described by previous authors.

There is, however, an important difference associated to the location of the wind speed measures used to scale the variables. When the wind data from the coastal stations is used, the growth rates 
increase considerably (e.g. Table 3 num. 6). When pure wind sea is taken the source of wind speed becomes an important source of uncertainty in calculating wave growth. In this area, the wind speed at the most offshore buoy is suspected to be the most representative of the wind speed of the measured waves at buoys $\mathrm{A}, \mathrm{B}$ and $\mathrm{E}$ because the growth rates are closest to the rates reported in $\mathrm{KC} 92$. Note that even though Cateura et al. (2004) reported the winds at EMA-U to be the most representative at buoy E during offshore wind regimes, the discrepancies at $\mathrm{E}$ when using winds from EMA-U are larger than when using winds from buoy $\mathrm{A}$. The remaining discrepancies in $\mathrm{B}$ and $\mathrm{E}$ are thought to be due to the lack on in-situ wind speeds to scale the variables.

In the region of study, the observed growth functions agree well with previously reported functions if certain conditions are closely met. Namely, pure wind sea conditions (no swell or old sea), and choosing a representative wind speed to scale the variables. If in-situ wind speed is not available, a good approximation is to use offshore wind speeds; especially during high wind speed conditions during which the variability of the wind fields is importantly reduced.

\section{WAVE GROWTH CURVES USING SIMULATED WIND AND WAVE DATA}

We have used SWAN model version 40.72ABCDE (Ris 1997) at $1 \mathrm{~km}$ resolution to hindcast a specific fetch-limited event (7-13 Dec. 2007) and to explore the performance of the model in reproducing the wave growth functions calculated in previous section. Forcing wind fields were obtained using MM5 atmospheric model at $4 \mathrm{~km}$ spatial resolution and $3 \mathrm{~h}$ temporal resolution. The directional resolution of the wave model was set to $10^{\circ}$, and the frequencies were distributed logarithmically $(\Delta \mathrm{f} / \mathrm{f}=0.119)$ between $0.01-1 \mathrm{~Hz}$. The computational time step was set to $20 \mathrm{~min}$. We used the default wind growth source functions, quadruplet interactions and whitecapping sink functions, which are due to Komen et al. (1984). The numerical method used was the BSBT scheme (backward space, backward time). The bottom friction was not activated and neither were the triads because shallow water processes are supposed to be much less important during the present conditions. Details on the model settings can be found in Alomar et al. (2009).

Wave height has been retrieved at each buoy's position on an hourly basis. An important wave height under-prediction was observed even though modeled wind speeds were very accurate (Alomar et al. 2009). Simulated wave energy during the subset of pure fetch-limited conditions has been nondimensionalized using in-situ modeled wind data. Non-dimensional energy has been plotted against non-dimensional fetch as in previous sections (Figure 3; results are included in Table 5). The resulting wave growth rates are smaller than those derived from the observations. This result is consistent with the wave height under-predictions reported in Alomar et al. (2009). The mean growth rates are also lower than the rates in KC92. Although there is a 95\% of probability that the observed data agree with the previously-reported functions the scatter of the curves is important. When using the wind speed from a location on the coast to scale the variables (e.g. H-met; see Table 5), we observe that growth rates largely increase compared to using in-situ wind data and they deviate considerably from the functions in $\mathrm{KC} 92$. When using winds from the position of buoy A the obtained growth rates are very close to the rates calculated using in-situ winds. But they are still smaller than both the reference functions and the observations (see Figure 3). These results support the idea that during the selected conditions, to scale the variables we can use both in-situ and offshore wind speeds and the observed curves would still agree with the functions in KC92. It can either be because wind data at an offshore position is representative enough of the data along the other buoys fetch, or because the wind along the fetch is less variable during high wind speed conditions. Again, data that deviate importantly from the reference curves usually correspond to mixed sea/old sea conditions. The importance of adjusting the fetch to the wind direction is not seen to be relevant either.

\begin{tabular}{|c|c|c|c|c|c|c|c|c|c|}
\hline \multirow[t]{2}{*}{ № } & \multirow{2}{*}{$\begin{array}{l}\text { Scaling wind } \\
\text { location }\end{array}$} & \multicolumn{2}{|c|}{$A$} & \multicolumn{2}{|c|}{$B$} & \multicolumn{2}{|c|}{$E$} & \multicolumn{2}{|c|}{ All buoys } \\
\hline & & B & SI & $b$ & SI & $b$ & SI & b & SI \\
\hline s1 & In-situ & 0.77 & 0.38 & 0.91 & 0.41 & 0.77 & 0.45 & 0.77 & 0.41 \\
\hline s2 & Buoy A & 0.77 & 0.38 & 0.66 & 0.38 & 0.77 & 0.59 & 0.77 & 0.43 \\
\hline s3 & $\mathrm{H}$-met & 1.64 & 0.39 & 1.55 & 0.34 & 1.85 & 0.52 & 1.33 & 0.53 \\
\hline
\end{tabular}



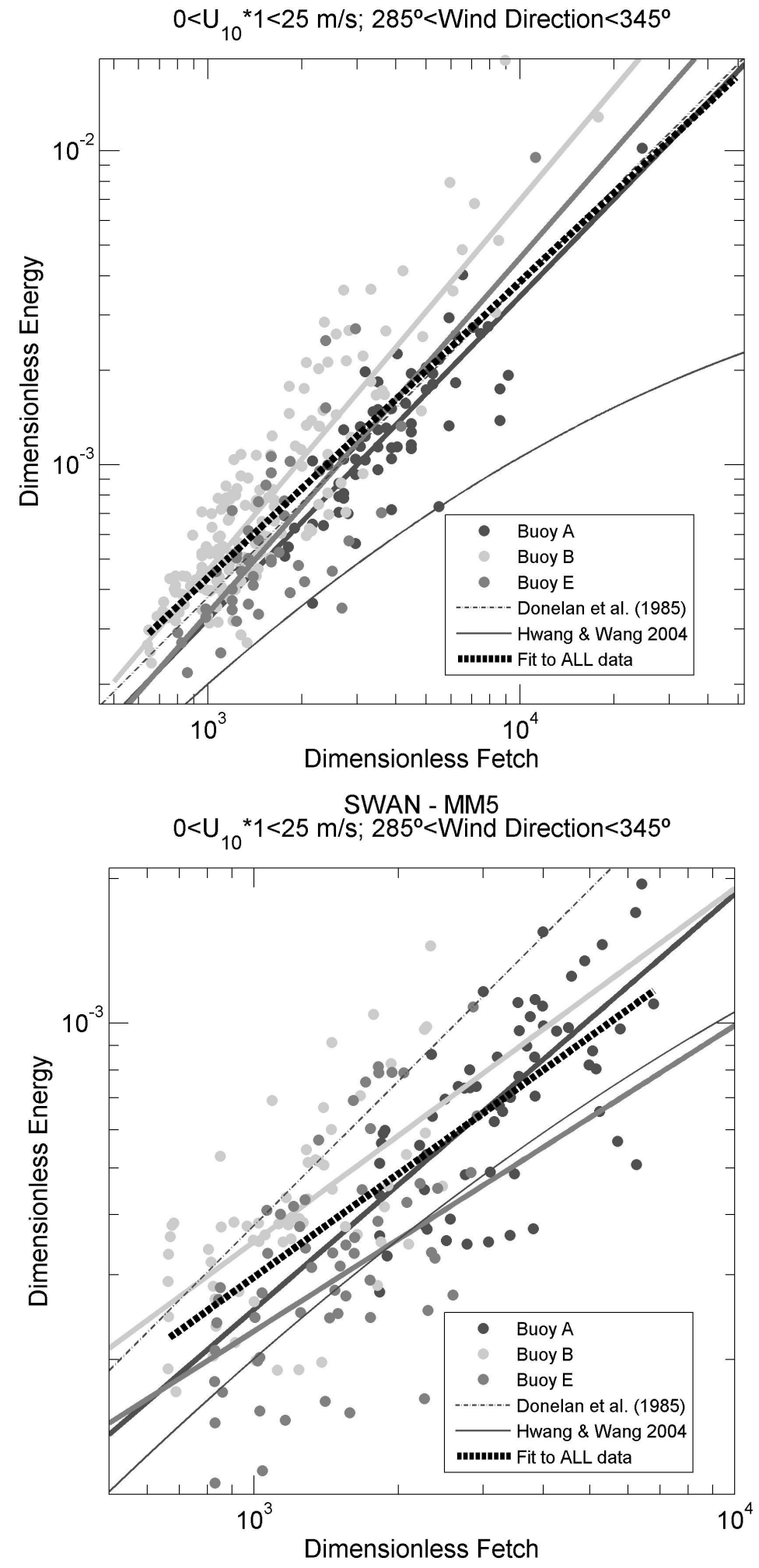

Figure 3. Non-dimensional curves at buoys A, B and E during a subset of fetch-limited data in storm conditions ( $7.125 \mathrm{~h}$ to $8.1215 \mathrm{~h} \& 9.1220 \mathrm{~h}$ to $11.1213 \mathrm{~h}$ ). Observed data (upper figure), and simulated data (lower figure). The wind speeds to scale the variables have been taken from buoy A. Solid lines indicate the fit to the data points (same color code). The functions reported in Donelan et al. (1985) and Hwang and Wang (2004) are also plotted. 


\section{CONCLUSIONS}

In the region of study, the characteristic land-to-sea wind regimes provide perfect conditions to study fetch-limited wave growth during variable wind conditions both in time and space. We have explored the adjustment of the locally calculated curves to previous studies (reviewed in KC92). The results indicate that the development rates tend to be higher than the reference functions when the conditions of homogeneity and stationarity are not closely met. The main discrepancies occur when encountering high sea states during low wind speed conditions. To make sure that no extra energy is accounted for in the calculations the emphasis should be placed into accurately separating sea, old sea, and swell. The role of old sea in the growth process should be further studied.

Another important source of discrepancy between the calculated curves and the functions in KC92 is thought to be the scaling wind speed. Our results suggest that using in-situ wind speed measurements reduces the discrepancies with the reference functions, even though it might not be the most representative wind along the fetch. If no in-situ wind data is available, we observe that measurements at an offshore buoy are also representative of the winds along the fetch, especially during storm conditions. Adjusting the fetch to the wind direction was seen to play a minor role in reducing the discrepancies observed between the calculated and the reference functions.

The present results indicate that when the theoretical conditions described by Kitaigorodskii (1962) are closely fulfilled our data approximately agrees with the results reported by previous authors. Growth rates from the simulated storm event indicate that growth rates in the model are lower than observed and lower than in KC92. The scatter of the results suggests that further analyses are to be performed.

To calculate more accurate growth functions in the area of study we suggest using a larger amount of data to discriminate homogeneous wind conditions from variable wind regimes, and low and high wind speed situations. In-situ wind speed measures would be desirable to scale the variables. Further work will compare increasing, decreasing and stable wind speed conditions, and the role of old sea on wave growth. Although in this study we have focused in studying wave energy growth, this is only the preliminary step before studying the rate of growth of the frequency peak under variable wind conditions.

\section{APPENDIX}

The non-dimensional energy $(\bar{E})$ and/or the frequency are usually plotted in logarithmic axis. The regression line that fits the data can be written as follows:

$$
\log (\bar{E})=a_{0}+b \cdot \log (\bar{X})
$$

In non logarithmic axis the change of energy along the fetch can be written as:

$$
\bar{E}=a \cdot \bar{X}^{b}
$$

Where $\mathrm{b}$ is also called development rate, and describes the rate of growth of the energy along the fetch. The origin is $a=\exp \left(a_{0}\right)$. Note that the factor $\mathrm{g} / \mathrm{U}^{2}$ is used to non-dimensionalize the variables in both $\mathrm{x}$ - and $\mathrm{y}$ - axis:

$$
\begin{aligned}
& \bar{E}=g^{2} \times E / U^{4} \\
& \bar{X}=g \times X / U^{2}
\end{aligned}
$$

Eq. A-4 is Eq. A-2 as a function of Eq. A-3, rearranged:

$$
\overline{\mathrm{E}}=\frac{\mathrm{g}^{2} \cdot \mathrm{E}}{(g \cdot X / \bar{X})^{2}}=\frac{\mathrm{E}}{X^{2}} \cdot \bar{X}^{2}
$$

In a log-log representation, Eq. A-4 can be written as Eq. A-5, where the factor of 2 between the variables in both axes is soon evident. Even if no correlation between the variables exists, there will always be a misleading spurious correlation due to the factor $\mathrm{g} / \mathrm{U}^{2}$ on both sides of Eq. A-1, which inherent relation is equal to 2 .

$$
\log (\bar{E})=\log \left(\mathrm{E} / \mathrm{X}^{2}\right)+\mathbf{2} \cdot \log (\bar{X})
$$




\section{ACKNOWLEDGEMENTS}

The authors would like to thank the European project FIELD_AC (FP7-SPACE-2009-1 n²42284) and the Spanish project RIMA (MEC, TRA2006-05132/TMAR). Buoy data was provided by the XIOM network and Puertos del Estado. Meteorological data were provided by the SMC and the ECMWF.

\section{REFERENCES}

Alomar, M., R. Bolaños, A. Sanchez-Arcilla, A. Sairouni, and F. Ocampo-Torres. 2009. Uncertainties in wave modeling for fetch-limited growth conditions. 33rd IAHR Congress: Water engineering for a sustainable environment, Vancouver, Canada, 2846-2853.

F. Ardhuin, T. H. C. Herbers, G. P. van Vledder, K. P. Watts, R. Jensen, and H. C. Graber. 2007. Swell and Slanting-Fetch Effects on Wind Wave Growth. Journal of Physical Oceanography, 37 (4), 908-931.

R. Bolaños, G. Jorda, J. Cateura, J. Lopez, J. Puigdefabregas, J. Gomez, and M. Espino. 2009. The XIOM: 20 years of a regional coastal observatory in the Spanish Catalan coast. Journal of Marine Systems, 77 (3), 237-260.

M. Bottema, and G. P. van Vledder. 2009. A ten-year data set for fetch- and depth-limited wave growth. Coastal Engineering, 56 (7), 703-725.

Cateura, J., A. Sánchez-Arcilla, and R. Bolaños. 2004. Wind climate at the Ebro delta and its relation with the sea state - clima de viento en el delta del ebro. Relación con el estado del mar. El clima, entre el mar y la montaña : IV Congreso de la Asociación Española de Climatología.

F. Dobson, W. Perrie, and B. Toulany. 1989. On the deep-water fetch laws for wind-generated surface gravity waves. Atmosphere-Ocean, 27 (1), 210-236.

M. A. Donelan, J. Hamilton, and W. H. Hui. 1985. Directional Spectra of Wind-Generated Waves. Philosophical Transactions of the Royal Society of London.Series A, Mathematical and Physical Sciences, 315 (1534), 509-562.

W. M. Drennan, H. C. Graber, D. Hauser, and C. Quentin. 2003. On the wave age dependence of wind stress over pure wind seas. Journal of Geophysical Research, 108 .

K. Hasselmann, T. P. Barnett, E. Bouws, D. E. Carlson, D. E. Cartwright, K. Enke, J. A. Ewing, H. Gienapp, D. E. Hasselmann, P. Kruseman, A. Meerburg, P. Müller, D. J. Olbers, K. Richter, W. Sell, and H. Walden. 1973. Measurements of wind-wave growth and swell decay during the Joint North Sea Wave Project (JONSWAP). Deutsche Hydrographische Zeitschrift, 8 (12), 1-95.

P. A. Hwang. 2008. Observations of swell influence on ocean surface roughness. Journal of Geophysical Research, 113 C12024.

P. A. Hwang, and D. W. Wang. 2004. Field measurements of duration-limited growth of windgenerated ocean surface waves at young stage of development. Journal of Physical Oceanography, 2316-2326.

K. K. Kahma. 1981. A study of the growth of the wave spectrum with fetch. Journal of Physical Oceanography, 1503-1515.

K. K. Kahma, and C. J. Calkoen. 1992. Reconciling discrepancies in the observed growth of windgenerated waves. Journal of Physical Oceanography, 1389-1405.

S. A. Kitaigorodskii. 1962. Applications of the theory of similarity to the analysis of wind-generated wave motion as a stochastic process. Bulletin Academy of Sciences, USSR Geophysics Series, (1), 105-107.

Komen, G. J., Cavaleri, L., Donelan, M., Hasselmann, K., Hasselmann, S., and Janssen, P. A. E. M. (1994). Dynamics and modelling of ocean waves. Cambridge University Press, Cambridge, UK.

G. J. Komen, K. Hasselmann, and K. Hasselmann. 1984. On the existence of a fully developed windsea spectrum. Journal of Physical Oceanography, 14 (8), 1271-1285.

Pettersson, H. 2004. Wave growth in a narrow bay. PhD thesis, Finnish Institute of Marine Research, Helsinki, Finland.

J. Portilla, F. J. Ocampo-Torres, and J. Monbaliu. 2009. Spectral Partitioning and Identification of Wind Sea and Swell. Journal of Atmospheric and Oceanic Technology, 107-122.

Ris, R. C. 1997. Spectral modelling of wind waves in coastal areas. PhD thesis, Delft University Press, Delft, Netherlands.

I. R. Young, and L. A. Verhagen. 1996. The growth of fetch limited waves in water of finite depth. Part 1. Total energy and peak frequency. Coastal Engineering, 29 (1-2), 47-78. 